\title{
Demanda judicial da populaçáo transexual na 2a Instância do Tribunal de Justiça do Estado do Rio de Janeiro: uma análise das decisóes até 2017
}

\author{
I ${ }^{1}$ Dulcinéa Peixoto Nelson, ${ }^{2}$ Vania Reis Girianelli, ${ }^{3}$ Sandra Maria Besso, \\ ${ }^{4}$ Danielle Barata Silva I
}

Resumo: Este artigo tem como objetivo analisar as decisôes judiciais na $2^{a}$ instância do Tribunal de Justiça do Estado do Rio de Janeiro (TJRJ) referentes às demandas da população transexual disponíveis até 2017. Os dados foram acessados no sítio eletrônico do TJRJ e analisados com base nas legislaçôes e normas vigentes. $\mathrm{O}$ estudo identificou 44 recursos, sendo que a maioria (32) para retificação do sexo no registro civil. Destes, 21 foram providos $(65,6 \%)$, sendo que em $12(57,1 \%)$ os apelantes não tinham realizado cirurgia de transgenitalização. $\mathrm{O}$ contingente de práticas na esfera política e social contribuiu para que a maioria dos recursos fosse provida antes do julgamento da Ação Direta de Inconstitucionalidade (ADI 4275) pelo Supremo Tribunal Federal, que visa ao reconhecimento dos transexuais à substituição de prenome e sexo no registro civil, independentemente da cirurgia de transgenitalizaçáo. Contudo, a tutela do Estado permanece, restringindo a autonomia e direitos dessa população.

> Palavras-chave: pessoas transgênero; Poder Judiciário; direitos humanos; identidade de gênero; disforia de gênero.

\author{
${ }^{1}$ Escola Nacional de Saúde Pública \\ Sergio Arouca, Fundação Oswaldo \\ Cruz. Rio de Janeiro-RJ, Brasil \\ (741consult@gmail.com). \\ ORCID: 0000-0003-4592-8200. \\ 2 Escola Nacional de Saúde Pública \\ Sergio Arouca, Fundação Oswaldo \\ Cruz. Rio de Janeiro-RJ, Brasil \\ (vaniagirianelli@yahoo.com.br). \\ ORCID: 0000-0002-8690-9893. \\ ${ }^{3}$ Instituto de Estudos em Saúde \\ Coletiva, Universidade Federal do \\ Rio de Janeiro. Rio de Janeiro-RJ, \\ Brasil (sm.besso@gmail.com). \\ ORCID: 0000-0003-2481-5469. \\ ${ }^{4}$ Escola Nacional de Saúde Pública \\ Sergio Arouca, Fundação Oswaldo \\ Cruz. Rio de Janeiro-RJ, Brasil \\ (daniellebarata@gmail.com). \\ ORCID: 0000-0003-3969-4751.
}

Recebido em: 19/12/2018 Aprovado em: 17/05/2019 Revisado em: 30/07/2019 


\section{Introdução}

O processo de redemocratização que se iniciou no final da década de 70 buscou restabelecer, além dos direitos políticos, os direitos fundamentais de grupos historicamente excluídos. A Constituição Federal (BRASIL, 1988) incorporou grande parte das reivindicaçôes de diferentes movimentos sociais e de compromissos assinados em tratados internacionais, servindo de base para elaboração de novas leis (CARRARA, 2012).

A garantia desses direitos, no entanto, não atinge a população de lésbicas, gays, bissexuais, travestis e transexuais (LGBT). A legislação que possibilita a obtenção dos direitos desta população ainda é incipiente e prescinde da ação dos movimentos sociais, que, mobilizados e articulados, aos poucos vêm logrando conquistas. Dentre elas, ressaltam-se o reconhecimento legal das relaçóes afetivas (BRASIL, 2011a e 2011b), o uso do nome social (BRASIL, 2016) e o acesso às políticas de saúde específicas (BRASIL, 2011c; 2011d). Na área da saúde, destaca-se o direito da pessoa transexual à realização de cirurgia de redesignação sexual pelo SUS e à assistência a todo o processo transexualizador (BRASIL, 2008a; 2013a; 2013b). Os direitos alcançados são provenientes de lutas dos movimentos sociais, bem como da atuação do Poder Judiciário, de instâncias do Ministério Público e da Defensoria Pública. Observa-se que até mesmo as açôes que não obtiveram êxito em seus pleitos possibilitaram um caminho para avanços obtidos. Nesse caminho, conquistas materializadas por intermédio de portarias se fazem presentes, sendo, entretanto, as mesmas suscetíveis de revogação. Ademais, a demanda é muito maior do que a oferta de serviços de saúde e vai além das transformações estéticas (ROCON et al., 2016).

Estudo que analisou a vulnerabilidade legislativa das leis federais específicas para sete grupos minoritários (idosos, pessoas com deficiência, LGBT, índios, mulheres, crianças e adolescentes) identificou que apenas a população LGBT apresentou fraca proteção legislativa, ou seja, nenhuma lei federal na área cível, processual, penal, administrativa e trabalhista (PAULA. et al., 2017).

Visando diminuir tal vulnerabilidade legislativa, no ano de 2019, o Supremo Tribunal Federal julgou a Ação Direta de Inconstitucionalidade por Omissão (ADO 26), reconhecendo como crime de racismo a discriminaçáo e os discursos de ódio contra a população LGBTI+, tendo o Ministro Relator Celso de Melo. 
em seu discurso. condenado o imobilismo do legislativo em proteger a população LGBT (BRASIL, 2019).

O termo vulnerabilidade possui estrita relação com o movimento de Direitos Humanos e refere-se a indivíduos ou grupos fragilizados política e juridicamente, na garantia dos seus direitos à cidadania. A partir da década de 80 , pesquisadores ampliaram este conceito na área da saúde pública para a suscetibilidade de pessoas e grupos ao adoecimento, considerando as dimensóes individual, programática e social (NICHIATA et al., 2008). Desta maneira, a população LGBT pode ser apontada como vulnerável, em particular travestis e transexuais, que apresentam maior risco de assassinato motivado por ódio, principalmente no Brasil, com cerca de 40\% das notificaçôes do mundo (BALZER; BERREDO, 2016).

Travestis e transexuais são indivíduos que se identificam com um gênero diferente do seu nascimento, e fazem parte do grupo transgênero (JESUS, 2012). As travestis vivenciam papéis de gênero feminino, mas se reconhecem como um terceiro gênero ou não gênero. Já as pessoas transexuais reivindicam o reconhecimento como homem ou mulher, sendo designadas quanto à identidade de gênero como homem trans e mulher trans, respectivamente. Esta identificação pode ocorrer de forma transitória ou persistente (APA, 2014). Quando a divergência entre o gênero percebido e concebido gera sofrimento, o indivíduo é diagnosticado com disforia de gênero. A construção da realidade destes sujeitos se dá através da crença de que a produção de documentos tem o poder de fabricar, criar, reforçar, modificar e desfazer mundos sociais.

[...] É essa mesma crença que sustenta a promessa de "transformação de homens em mulheres" e vice-versa que perpassa toda a visão da "terapia de mudança de sexo", como a "cura" para a "disforia de gênero", que tem na cirurgia de transgenitalização e na subsequente alteração do registro civil seu ápice, permitindo que a pessoa reconstrua e recomece sua vida "do zero" e de acordo com sua "verdadeira identidade" (FREIRE, 2016).

Apesar do reconhecimento científico da existência de transexuais e dos avanços terapêuticos para minimizar o sofrimento desta população, o acesso às modificaçōes corporais e à alteração da sua situação legal só é possível a partir da tutela da Medicina e do Direito. Estas limitações e restrições impactam no exercício da autonomia do sujeito, refletindo negativamente na sua saúde (VENTURA; SCHRAMM, 2009).

Os efeitos de uma norma jurídica dependem de sua efetividade social e jurídica (NADER, 2017). A efetividade social implica no reconhecimento e reivindicação 
do direito pela sociedade. Já a efetividade jurídica ocorre quando é aplicada pelos magistrados. Tem-se que o processo decisório, por sua complexidade, extrapola a aplicação de princípios e leis. Para acesso à Justiça, o transgênero precisa comprovar sua qualidade de "sujeito de direito" (FREIRE, 2016), ou seja, "verdadeiros transexuais" (MEYER III et al., 2001), que em última análise significa ter diagnóstico médico de "disforia de gênero".

Em 2009, a Procuradora-Geral da República ingressou com Ação Direta de Inconstitucionalidade (ADI 4275) visando ao reconhecimento dos transexuais à substituição de prenome e sexo no registro civil, independentemente da cirurgia de transgenitalização (BRASIL, 2009a). A partir desta ação, passou a tramitar Recurso Extraordinário (RE) 670422, com repercussão geral reconhecida, para autorizar a alteração do registro civil de pessoa transgênero, diretamente pela via administrativa, independentemente da realização de procedimento cirúrgico de redesignação de sexo (BRASIL, 2012). A decisão de ambas foi finalizada pela Suprema Corte em 2018 de forma favorável.

O objetivo deste estudo é analisar os acórdãos decididos pelos desembargadores no Tribunal de Justiça do Estado do Rio de Janeiro (TJRJ) referentes às demandas judiciais da população transexual, disponíveis até 2017. ${ }^{1}$

\section{Metodologia}

Trata-se de estudo descritivo sobre as demandas judiciais da populaçáo transexual, sendo elegíveis os recursos que tramitaram na $2^{\text {a }}$ instância do TJRJ e disponíveis até 31 de dezembro de 2017. Os dados foram acessados no site do TJRJ em 30 de junho de 2018, utilizando os descritores "transexuais" ou "transgêneros" e "transexualidade". As variáveis estudadas compreenderam as características dos autores (identidade de gênero e realização de cirurgia de transgenitalização ou mastectomia), da demanda (mudança de prenome, sexo, solicitação de cirurgia etc.) e do processo (ano da entrada e julgamento do recurso, tempo de tramitaçáo, tipo de recurso e resultado do julgamento); restringindo-se às informaçôes que sáo de acesso público.

Os dados foram armazenados e consolidados no Microsoft Office Excel, versão 2013. Calculou-se a proporção das categorias de cada variável estudada. A análise dos resultados baseou-se nas legislaçôes e normas vigentes. 


\section{Resultado e Discussão}

O estudo encontrou 45 recursos julgados na $2^{\text {a }}$ Instância do Tribunal de Justiça do Estado do Rio de Janeiro até 31 de dezembro de 2017, mas o primeiro recurso foi interposto em 2002. Destes, 40 foram identificados utilizando os descritores "transexuais" ou "transgêneros" e cinco com "transexualidade", sendo que um constava em ambos.

Dentre os 44 recursos analisados, seis foram impetrados pelo Ministério Público. Destes, dois solicitavam a anulaçáo da sentença na 1a Instância, que havia autorizado apenas mudança de prenome, e redistribuição para Vara de Família. Ambos foram julgados procedentes em 2017. Outros dois recursos de apelação referiam-se ao inconformismo com a decisão da sentença na $1^{\text {a }}$ Instância que autorizou alterar o sexo no registro civil sem realização de cirurgia. Ambos foram julgados improcedentes, sendo um em 2014 e o outro, em 2017. Em outro recurso, o Ministério Público arguiu que o pedido de alteração de sexo no registro de nascimento não constava da petição inicial; sendo permitida a averbação nos livros de registros, sem referência ao fato de que a alteração é oriunda de decisão judicial ou por motivo de cirurgia de mudança de sexo. E a outra foi uma ação civil pública contra parlamentar municipal que fez declaração homofóbica e discurso de ódio para integrantes de comunidade LGBT em rede social, sendo solicitado dano moral coletivo, a ser revertido em prol desta população. Esta foi julgada improcedente em 2015, considerando que, apesar de a conduta ter sido reprochável, não tem relevância social necessária para o prejuízo extrapatrimonial alegado. Os desembargadores consideraram que o instituto do dano moral coletivo é novo no cenário jurídico brasileiro, e o alargamento deste conceito ensejaria efeito não desejado, de modo a restringir a liberdade de expressão, tornando indenizável aquilo que está adstrito à esfera da ética e da moral. Adicionalmente, entenderam que a imposiçáo de uma reparação civil representaria excesso e desvio do sentido e conceito jurídico.

Dos 38 recursos impetrados por pessoa física, dois referiam-se a agravos de instrumento cujos apelantes não eram transexuais. Um objetivava retirar todo o conteúdo jornalístico relacionado à publicação na mídia de fotografia de um jantar romântico do apelante ao lado de uma pessoa transexual, sob o fundamento de que teria sido violada a imagem, bem como solicitação de dano moral. Os 
desembargadores argumentaram que o reconhecimento do dano corresponderia tutelar um comportamento contraditório e preconceituoso. No outro, o apelante requereu redução da indenização por dano moral proferido na $1^{\text {a }}$ Instância, devido à agressão cometida por seguranças na saída da quadra da escola de samba contra dois transexuais, sendo indeferido em 2008. Também foi impetrado um recurso de apelação referente à indenização por erro médico, devido à insatisfação do autor com o resultado da cirurgia de implante de silicone nas mamas. Este processo foi julgado procedente, mas a condenação correspondeu a menos de $20 \%$ do valor pleiteado.-

Os demais 35 recursos referiam-se a demandas relacionadas à solicitação de cirurgia, substituição de prenome e sexo no registro civil. A maioria dos apelantes era mulher trans $(88,6 \%)$, mas em um acórdão não tinha informação sobre sexo e identidade de gênero. Cerca de um terço das mulheres e dos homens trans tinha informação de ser transgenitalizada e mastectomizado, respectivamente (tabela 1).

Tabela 1. Características dos apelantes nos recursos impetrados na $2^{\text {a }}$ Instância do Tribunal de Justiça do Estado do Rio de Janeiro, até 2017

\begin{tabular}{lll}
\hline Características & N & \% \\
\hline Identidade sexual & 31 & 88,6 \\
Mulher trans & 3 & 8,6 \\
Homem trans & 1 & 2,9 \\
Ignorado & & \\
Transgenitalizado & \\
Sim & 9 & 29,0 \\
Não & 19 & 61,3 \\
Sem informação & 4 & 12,9 \\
Mastectomizado & & \\
Sim & & 33,3 \\
Não & 1 & 66,7 \\
\hline
\end{tabular}

\footnotetext{
${ }^{a}$ Denominador apenas mulheres trans.

${ }^{\mathrm{b}}$ Denominador apenas homens trans.

Fonte: elaboração própria.
} 
A tabela 2 apresenta as características dos recursos impetrados. A maioria era recurso de apelação ${ }^{2}(82,9 \%)$, foi distribuída e julgada após 2009 (77,1\% e $80,0 \%$, respectivamente), num intervalo menor que seis meses $(74,3 \%)$, e dado provimento $(62,9 \%)$.

Tabela 2. Características dos recursos impetrados na 2a Instância do Tribunal de Justiça do Estado do Rio de Janeiro, até 2017

\begin{tabular}{lll}
\hline Características & N & $\%$ \\
\hline
\end{tabular}

Tipo de ação

Recurso de apelação ${ }^{a}$

Agravo de instrumento

6

17,1

Ano de entrada na 2a Instância

2002 a 2009

8

2010 a 2017

77,1

Ano de julgamento na $2^{\mathrm{a}}$ Instância

2002 a 2009

2010 a 2017

80,0

Intervalo entre entrada e julgamento

$<6$ meses

26

74,3

6 a 12 meses

6

17,1

$>12$ meses

3

8,6

Acórdão

Provido 22 62,9

Improvido

8

22,9

Parcialmente provido

3

8,6

Não Conhecido 2 5,7

${ }^{a}$ Recurso processual interposto contra a sentença proferida por juiz de primeiro grau.

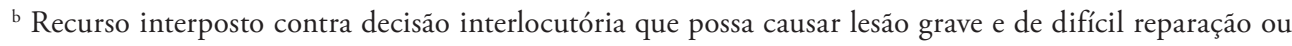
decisão posterior à sentença que inadmita apelaçấo ou negue efeito suspensivo à apelaçáo.

${ }^{\mathrm{c}}$ Recurso não preenche os requisitos básicos para admissibilidade.

Fonte: elaboração própria. 
O aumento de recursos em tramitação a partir de 2009 reflete os esforços dos movimentos sociais para dar visibilidade às demandas da população LGBT. As pressôes sociais contribuíram para a formulação e implantação de políticas públicas, destacando-se: Brasil sem Homofobia - Programa de Combate à Violência e à Discriminação LGBT e de Promoção à Cidadania Homossexual (BRASIL, 2008b), Primeira Conferência Nacional LGBT de Promoção à Cidadania e Direitos Humanos de LGBT (BRASIL, 2008c), Programa Nacional de Direitos Humanos (PNDH-3) (BRASIL, 2009b) e, principalmente, a divulgação do Relatório de Monitoramento das Açóes do Plano Nacional de Promoção da Cidadania e Direitos Humanos de LGBT (PNPCDH-LGBT) (BRASIL, 2010). Na área da saúde, o marco é a Política Nacional de Saúde Integral LGBT (BRASIL, 2011c), no qual o processo transexualizador está inserido e posteriormente é instituído na rede SUS (BRASIL, 2013b). Além do marco histórico do Supremo Tribunal Federal (STF) que deu provimento à Ação Direta de Inconstitucionalidade (ADI) 4275 e ao Recurso Extraordinário (RE) 670422, para autorizar a alteraçáo do registro civil de pessoa transgênero, diretamente pela via administrativa, independentemente da realização de procedimento cirúrgico de redesignação de sexo.

A tabela 3 apresenta os objetos das demandas e respectivas decisões dos acórdãos. A maioria dos recursos impetrados (32) era para retificação do sexo no registro civil (91,4\%). Destes, 21 acórdãos foram providos (65,6\%), sendo que em 12 (57,1\%) os apelantes não tinham realizado cirurgia de transgenitalização. Dos acórdãos providos, quatro foram julgados em data anterior à tramitação da ADI 4275, mas os autores haviam realizado a cirurgia de transgenitalizaçáo. 
| Página 9 de 16

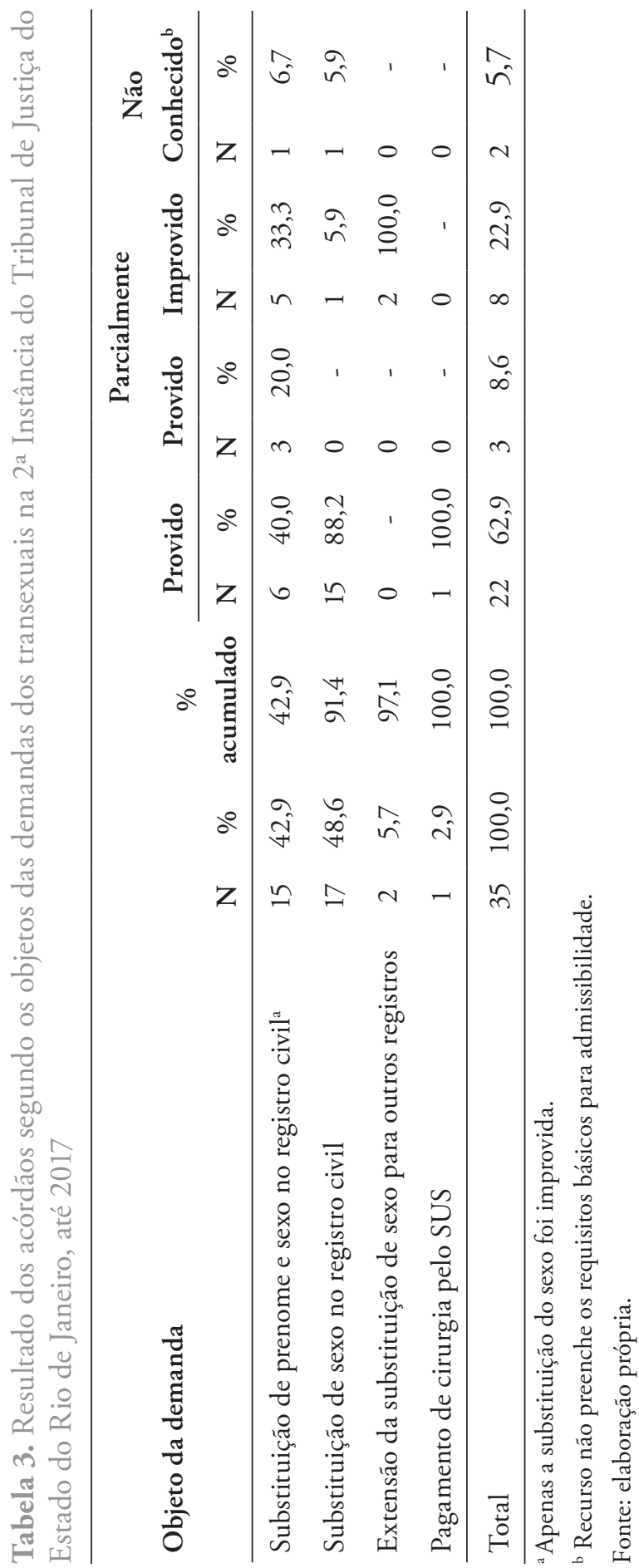


Por outro lado, dentre os nove acórdãos improvidos em relação à retificação do sexo no registro civil, em um a decisão ocorreu em 2005, apesar da comprovação do autor de ter se submetido à cirurgia de transgenitalização. Os demais recursos foram julgados após a tramitação da ADI 4275, sendo que sete depois do alcance da repercussão geral sobre a matéria. A maioria das alegaçôes ressaltou ser imprescindível a realização da cirurgia de transgenitalização, para deferimento dos pedidos de mudança de sexo nos assentos dos registros de nascimento. Apenas uma das câmaras cíveis mencionou a ADI 4275 tramitando no STF; porém, se manteve em igualdade com a decisão das demais (BRASIL, 2009a). Em dois casos, foi dado prazo para incluir pareceres técnicos quanto aos aspectos físicos, psicológicos e sociais dos autores (dilação probatória).

Mesmo após o reconhecimento da repercussão geral pelo STF, as fontes de orientação sobre a matéria foram as recomendações e os conceitos disponibilizados no instrumento da Associação Internacional de Disforia de Gênero (MEYER III et al., 2001), na quinta versão do manual de diagnóstico de distúrbios mentais (APA, 2014) e na resolução do Conselho Federal de Medicina (CFM, 2010).

Os dois acórdãos considerados não conhecidos ou não admitidos referiam-se a agravos de instrumento de um mesmo processo originário, ambos contra o despacho do juiz da primeira instância, mas sem cunho decisório, e, portanto, irrecorrível por não trazer requisitos de admissibilidade (BRASIL, 2015). A razão da interposição deste agravo é o fato de terem os autos do processo originário sido sobrestados (suspensão temporária do processo), situação que permanece desde o mês de maio, data que antecedeu a interposição do agravo, pelo menos até dezembro de 2017.

Dos 15 requerimentos sobre mudança de prenome, nove foram providos (60,0\%). Dentre os cinco acórdãos improvidos, em três foi alegada a necessidade de cirurgia de transgenitalização, embora não esteja prevista na legislação; e nos demais foram estendidos o prazo para inclusão de parecer técnico comprobatório da transexualidade.

Duas demandas que tinham como objeto a extensão da requalificação civil também foram negadas. Numa, a pretensão era a extensão da alteração do sexo no registro de nascimento, alcançada na $1^{\text {a }}$ Instância, para certidão de casamento. $\mathrm{O}$ recurso foi negado na 22a Vara Cível, considerando que os efeitos modificativos extrapolam as relaçóes jurídicas do agravante com o Estado e a Sociedade. A outra 
requeria a substituição de "filho" e "nascido" para "filha" e "nascida". Neste caso, o autor havia se submetido a cirurgia de transgenitalização. Os desembargadores da 10a Câmara Cível negaram em 2007 a reforma da sentença, pois entenderam que o gênero é definido por análise citogenética, ou seja, através da contagem para identificar o cromossomo sexual do indivíduo, considerando que a operação de redesignação sexual não tem o condão de alterar a formação genética deste, mas apenas adequar o seu sexo biológico-visual ao psicológico, o que, de tal forma, levaria a sérias distorçôes. Segundo consta no acórdão, o potencial de risco e o direito de terceiros quanto ao desconhecimento da realidade fática que envolve o transexual foram considerados, bem como a preservação da intimidade e a honra de terceiros com quem ela trave relaçôes. Este recurso foi um dos elementos de prova juntados na $\mathrm{ADI} 4275$, trazendo à discussão o reconhecimento de direitos gerais e específicos dos transexuais (BRASIL, 1973; 1998; 2009a).

Outro recurso, que objetivou o pagamento de cirurgia de transexualização pelo Sistema Único de Saúde, foi ajuizado contra um município da região noroeste do estado. Os desembargadores entenderam que o pedido formulado pelo apelante foi fundamentado na efetivação do direito constitucional à saúde, com amparo nas garantias constitucionais, e nas disposiçôes contidas nas Leis 8.080 (BRASIL, 1990a) e 8.142 (BRASIL, 1990b).

\section{Considerações finais}

Os tribunais de Justiça vêm se mostrando como um espaço aberto à resolução de conflitos e de temas contemporâneos, como as demandas dos transexuais em busca da consolidação de seus direitos fundamentais. Nas situaçóes em que a lei é omissa, os critérios adotados para as decisóes devem estar de acordo com a analogia, os costumes e os princípios gerais de direito (BRASIL, 1942). Neste sentido, cabe aos magistrados recorrer ao amparo das resoluçôes e recomendaçóes que orientam os profissionais de múltiplas áreas relacionadas às demandas enfrentadas pelos transexuais. Elas são de suma importância para desvendar a complexidade das questôes que envolvem o tema transexualidade, principalmente porque a cirurgia de transgenitalização tornou-se o ponto de mais alto relevo a subsidiar as sentenças e acórdãos prolatados.

De igual forma, as ações sociais e políticas que surgiram no período, oriundas dos grupos ativistas LGBT, foram cruciais e passaram a reivindicar políticas públicas 
voltadas à promoção da cidadania e direitos humanos desta população. Embora este movimento seja considerado tardio, comparado a outros movimentos sociais, como o de mulheres e dos negros (RAMOS; CARRARA, 2006), percebe-se grande influência na formação da convicção dos julgadores.

Em razão da crescente demanda judicial, principalmente a partir de 2009, passou a tramitar no Supremo Tribunal Federal a Ação Direta de Inconstitucionalidade (ADI 4275), criando novas diretrizes para os magistrados. O contingente de práticas na esfera política e social contribuiu para que a maioria dos recursos fosse provida, antes do julgamento da Suprema Corte, mesmo sem a realização de cirurgia de transgenitalização.

Mesmo com julgamento favorável da ADI 4275 e de todos os avanços, a tutela do Estado, através da Medicina e do Judiciário, ainda permanece; restringindo a autonomia das pessoas transexuais ao acesso aos seus direitos fundamentais à dignidade, saúde e liberdade. ${ }^{3}$

\section{Referências}

AMERICAN PSYCHIATRIC ASSOCIATION (APA). Manual diagnóstico e estatístico de transtornos mentais: DSM-5. Porto Alegre: Artmed, 2014. p. 451-461.

BALZER, C.; BERREDO, L. TMM Annual Report 2016: 2,190 murders are only the tip of the iceberg. An introduction to the Trans Murder Monitoring project. Berlin: TGEU, 2016.

BRASIL. Presidência da República. Lei de Introdução às normas do Direito Brasileiro. DecretoLei n. 4.657, de 4 de setembro de 1942. Disponível em: <http://www.planalto.gov.br/ccivil_03/ decreto-lei/Del4657.htm>. Acesso em: 30 abr. 2018.

Presidência da República. Lei n. 6.015, de 31 de dezembro de 1973. Dispóe sobre os registros públicos e dá outras providências. Brasília: Presidência da República. Disponível em: <http://www.planalto.gov.br/ccivil_03/leis/L6015compilada.htm>. Acesso em: 26 jun. 2018.

. Senado Federal. Constituição da República Federativa do Brasil de 1988. Promulgada em 5 de outubro de 1988. Disponível em: <http://www.planalto.gov.br/ccivil_03/constituicao/ constituicao.htm >. Acesso em: 15 maio 2018.

Presidência da República. Lei n. 8.080, de 19 de setembro de 1990. Dispóe sobre as condições para a promoção, proteção e recuperação da saúde, a organização e o funcionamento dos serviços correspondentes e dá outras providências. Brasília: Presidência da República, 1990a. Disponível em: <http://www.planalto.gov.br/ccivil_03/leis/L8080.htm>. Acesso em 25 jun. 2018. 
. Presidência da República. Lei n. 8.142, de 28 de novembro de 1990. Dispóe sobre a participação da comunidade na gestão do Sistema Único de Saúde (SUS) e sobre as transferências intergovernamentais de recursos financeiros na área da saúde e dá outras providências. Brasília: Presidência da República. 1990b. Disponível em: <http://www.planalto.gov.br/ccivil_03/leis/ L8142.htm>. Acesso em: 25 jun. 2018.

Presidência da República. Lei n. 9.708, de 18 de novembro de 1998. Altera o art. 58 da Lei n. 6.015, de 31 de dezembro de 1973. Dispóe sobre Registros Públicos, para possibilitar a substituição do prenome por apelidos públicos notórios. Brasília: Presidência da República, 1998. Disponível em: <http://www.planalto.gov.br/ccivil_03/Leis/L9708.htm >. Acesso em: 26 jun. 2018.

. Ministério da Saúde. Portaria n. 457, de 19 de agosto de 2008. Aprova a Regulamentação do Processo Transexualizador no âmbito do Sistema Único de saúde (SUS). Brasília: Ministério da Saúde, 2008a. Disponível em: <http://bvsms.saude.gov.br/bvs/saudelegis/sas/2008/ prt0457_19_08_2008.html>. Acesso em: 15 jan.2018.

- Ministério da Saúde. Brasil sem Homofobia: programa de combate à violência e à discriminação contra GLBT e promoção da cidadania homossexual (BSH). Brasília: Ministério da Saúde, 2008b. Disponível em: <http://bvsms.saude.gov.br/bvs/publicacoes/brasil_sem_ homofobia.pdf>. Acesso em: 18 jan. 2018.

- Secretaria Especial dos Direitos Humanos. Direitos humanos e políticas públicas: o caminho para garantir a cidadania GLTB. In: Conferência de Gays, Lésbicas, Bissexuais, Travestis e Transexuais - GLBT. Anais... Brasília: Secretaria Especial dos Direitos Humanos, 2008c. Disponível em: <[http://www.mdh.gov.br/informacao-ao-cidadao/participacao-social/ old/cncd-lgbt/conferencias/anais-1a-conferencia-nacional-lgbt-2>. Acesso em: 14 abr. 2018.

. Supremo Tribunal Federal. Ação Direta de Inconstitucionalidade n. 4275, de 21 julho de 2009. Brasília: Supremo Tribunal Federal, 2009a. Disponível em: <http://www.stf.jus.br/ portal/geral/verPdfPaginado.asp?id=400211\&tipo=TP\&descricao=ADI\%2F4275>. Acesso em: 10 abr.2018.

- Presidência da República. Decreto n. 7.037, de 21 dezembro de 2009. Aprova o Programa Nacional de Direitos Humanos - PNDH-3 e dá outras providências. Brasília: Presidência da República, 2009b. Disponível em: <http://www.planalto.gov.br/ccivil_03/_ ato2007-2010/2009/decreto/d7037.htm>. Acesso em: 26 jun. 2018.

- Presidência da República. Relatório de monitoramento das açóes do plano nacional de promoção da cidadania e direitos humanos de LGBT (PNPCDH-LGBT). Brasília: Presidência da República, 2010. Disponível em: <http://www.rcdh.ufes.br/sites/default/files/ Relat\%C3\%B3rio\%20de\%20Monitoramento\%20do\%20Plano\%20Nacional\%20de\%20 Cidadania.pdf>. Acesso em: 25 maio 2018. 
. Supremo Tribunal Federal. Ação Direta de Inconstitucionalidade n. 4.277, de 5 de janeiro de 2011. Brasília: Supremo Tribunal Federal, 2011a. Disponível em: <http://redir.stf.jus. br/paginadorpub/paginador.jsp?docTP=AC\&docID=628635>. Acesso em: 26 jun. 2018.

. Supremo Tribunal Federal. Arguição de Descumprimento de Preceito Fundamental 132 - Rio de Janeiro. Brasília: Supremo Tribunal Federal. 2011b. Disponível em: <http://redir.stf.jus. br/paginadorpub/paginador.jsp?docTP=AC\&docID=628633>. Acesso em: 26 jun. 2018.

- Ministério da Saúde. Portaria n. 2.836, de $1^{\text {o }}$ de dezembro de 2011. Institui, no âmbito do Sistema Único de Saúde (SUS), a Política Nacional de Saúde Integral de Lésbicas, Gays, Bissexuais, Travestis e Transexuais (Política Nacional de Saúde Integral LGBT). Brasília: Ministério da Saúde, 2011c. Disponível em: <http://bvsms.saude.gov.br/bvs/saudelegis/ gm/2011/prt2836_01_12_2011.html>. Acesso em: 26 jun. 2018.

Ministério da Saúde. Politica Nacional de Saúde Integral de Lésbicas, Gays, Bisseuxais, Travestis e Transexuais - LGBT. Brasília: Ministério da Saúde, 2011d. Disponível em: <http://bvsms. saude.gov.br/bvs/publicacoes/politica_nacional_saude_lesbicas_gays.pdf>. Acesso em: 15 abr. 2018.

. Supremo Tribunal Federal. Recurso Extraordinário n. 670.422 - Rio Grande do Sul, de 26 janeiro de 2012. Brasília: Supremo Tribunal Federal. 2012. Disponível em: <http://www. stf.jus.br/portal/jurisprudenciaRepercussao/verAndamentoProcesso. asp? incidente $=4192182 \&$ numeroProcesso=670422\&classeProcesso=RE\&numeroTema=761>. Acesso em: 10 abr. 2018 .

Ministério da Saúde. Politica Nacional de Saúde Integral de Lésbicas, Gays, Bissexuais, Travestis e Transexuais. Brasília: Ministério da Saúde, 2013a. Disponível em: <http://bvsms.saude. gov.br/bvs/publicacoes/politica_nacional_saude_lesbicas_gays.pdf>. Acesso em: 30 abr. 2018.

- Ministério da Saúde. Portaria n. 2.803, de 19 de novembro de 2013. Redefine e amplia o Processo Transexualizador no Sistema Único de Saúde (SUS). Brasília: Ministério da Saúde, 2013b. Disponível em: <http://bvsms.saude.gov.br/bvs/saudelegis/gm/2013/ prt2803_19_11_2013.html>. Acesso em: 15 jun. 2018.

- Presidência da República. Código de Processo Civil. Lei n. 13.105, de 16 de março de 2015. Brasília: Presidência da República. 2015. Disponível em: < http://www.planalto.gov.br/ ccivil_03/_ato2015-2018/2015/lei/113105.htm>. Acesso em: 20 de jun. 2018.

Presidência da República. Decreto n. 8.727, de 28 de abril de 2016. Dispóe sobre o uso do nome social e o reconhecimento da identidade de gênero de pessoas travestis e transexuais no âmbito da administração pública federal direta, autárquica e fundacional. Brasília: Presidência da República. 2016. Disponível em: <http://www.planalto.gov.br/ccivil_03/_ato2015-2018/2016/ decreto/D8727.htm>. Acesso em: 30 abr. 2018.

. Supremo Tribunal Federal. Ação Direta de Inconstitucionalidadepor Omissão n. 26, de 13 junho de 2019. Brasília: Supremo Tribunal Federal, 2019. Disponível em: <https://portal.stf. jus.br/processos/detalhe.asp?incidente=4515053>. Acesso em: 15 jul. 2019. 
CARRARA, S. Discrimination, policies, and sexual rights in Brazil. Cadernos de Saúde Pública, v. 28, n. 1, p. 184-189, 2012.

CONSELHO FEDERAL DE MEDICINA. Resolução CFM no. 1.955/2010. Dispôe sobre a cirurgia de transgenitalismo e revoga a Resolução CFM no. 1.652/02. Diário Oficial da União. Brasília, DF, 3 set. 2010. Disponível em: <http:/www.portalmedico.org.br/resolucoes/ cfm/2010/1955_2010.htm>. Acesso em: 2 mar. 2018.

FREIRE, L. Sujeitos de papel: sobre a materialização de pessoa transexuais e a regulação de acesso a direitos. Cadernos Pagu, n. 48, e164813, 2016.

JESUS, J. G. Orientaçôes sobre a populaçâo transgênero: conceitos e termos. Brasília: Autor, 2012.

MEYER III, W. et al. The Harry Benjamin International Gender Dysphoria Association's Standards of Care for Gender Identity Disorders, Sixth Version, 2001. Disponível em: <http://www.cpath. ca/wp-content/uploads/2009/12/WPATHsocv6.pdf>. Acesso em: 15 abr. 2018.

NADER, P. Introdução ao estudo do direito. 39ª ed. Rio de Janeiro: Forense, 2017.

NICHIATA, L. Y. I. et al. A utilização do conceito "vulnerabilidade" pela enfermagem. Revista Latino-Americana de Enfermagem, v. 16, n. 5, p. 923-928, 2008.

PAUlA, C. E. A.; SILVA, A. P.; BITTAR, C. M. L. Vulnerabilidade legislativa de grupos minoritários. Ciência e Saúde Coletiva, v. 22, n. 12, p. 3841-3848, 2017.

RAMOS, S.; CARRARA, S. A constituição da problemática da violência contra homossexuais: a articulação entre ativismo e academia na elaboração de políticas públicas. Physis: Rev. Saúde Coletiva, v. 16, n. 2, p. 185-205, 2006.

ROCON, P. C. et al. Dificuldades vividas por pessoas trans no acesso ao SUS. Ciência e Saúde Coletiva, v. 21, n. 8, p. 2517-2525, 2016.

VENTURA, M.; SCHRAMM, F.R. Limites e possibilidades do exercício da autonomia nas práticas terapêuticas de modificação corporal e alteração da identidade sexual. Physis: Rev. Saúde Coletiva, v. 19, n. 1, p. 65-93, 2009.

\section{Notas}

${ }^{1}$ Este estudo faz parte do trabalho de conclusão do curso de Especialização em Direitos Humanos e Saúde da ENSP-Fiocruz, pela primeira autora, apresentado e aprovado em julho de 2018. As autoras declaram não haver conflitos de interesse. Não houve financiamento para este estudo.

${ }^{2}$ Recurso processual interposto contra a sentença proferida por juiz de primeiro grau.

${ }^{3}$ D. P Nelson foi responsável pela elaboração do trabalho, análise e interpretação dos dados e redação da primeira versão do manuscrito. V. R. Girianelli responsabilizou-se pela concepção, desenho do estudo, interpretação dos dados e revisão crítica do texto. S. M. Besso e D. B. Silva realizaram a interpretação dos dados e a revisáo crítica do texto. 


\section{Abstract}

Judicial demand of the transsexual population in the 2nd Instance of the Court of Justice of the State of Rio de Janeiro: an analysis of the decisions until 2017

This article aims to analyze the judicial decisions in the 2 nd instance of the Court of Justice of the State of Rio de Janeiro (TJRJ) regarding the demands of the transsexual population available until 2017. The data were accessed on the TJRJ website and analyzed based on legislation and current standards. The study identified 44 appeals, the majority (32) for rectification of sex in the civil registry. Of these, 21 were granted (65.6\%), and in $12(57.1 \%)$ the appellants had not undergone transgenitalization surgery. The contingent of practices in the political and social sphere contributed so that most appeals were granted before the Direct Unconstitutionality Action (ADI 4275) was judged by the Federal Supreme Court, which aims the recognition of transsexuals to the substitution of first name and sex in the civil registry, regardless of transgenitalization surgery. However, the State tutelage remains, restricting the autonomy and rights of this population.

Keywords: transgender persons; Judiciary; human rights; gender identity; gender dysphoria. 